\title{
Learning physics: from the nature and origins of difficulties to an evolution of teaching
}

\section{Models and modeling}

\author{
Valérie Munier $^{1}$ \\ LIRDEF, EA 3749, University of Montpellier et University Paul Valéry \\ 2 place M. Godechot, BP 4152, 34092 Montpellier Cedex 5, France \\ E-mail: valerie.munierafde.univ-montp2. fr
}

This paper deals with the difficulties encountered by students to develop and give meaning to models. We first present some results of a study conducted in a French university which points out studentsôdifficulties to model a ñreal wordò problem. In a second part we discuss the difficulties encountered by students when they have to construct a model from measurement data. For this we rely on research dealing with students difficulties concerning measurement and uncertainties, and we discuss how these difficulties can be an obstacle to understand the epistemological nature of models. In conclusion we propose some lines of thought for a teaching of physics taking into account more explicitly the question of models and modeling and allowing to develop studentsôreflection about the nature of science.

Frontiers of Fundamental Physics 14

FFP14

15-18 July 2014

Aix Marseille University (AMU) Saint-Charles Campus, Marseille

${ }^{1}$ Speaker

(c) Copyright owned by the author(s) under the terms of the Creative Commons Attribution-NonCommercial-ShareAlike Licence. 


\section{Introduction}

This paper deals with studentsôdifficulties about models and modeling in physics. This question of model and modeling is crucial in physics and in physics teaching, from elementary school to university. If we question the nature of physicistsô activity, we can answer that physicists aim at connecting experimental data and theoretical constructions.

Popper conceives « [é ] the scientific theories as human inventions - as nets created by us and intended to capture the world é They are never perfect instrumentsé » [1]. If scientists develop theories, they also develop and use, to solve a given problem, some simpler but functional tools: models. The models can then be considered as an intermediary between theoretical field and empirical field, and some epistemologists even consider that the modeling activity is the central task of the physicist [2].

\subsection{Modeling process}

According to Walliser [3], when we develop a model there are two opposite starting points (see figure 1). In the first case we develop a model from the theory. We start from a theoretical field and we develop a theoretical model by equating a system, this model having a hypothetical character to be confirmed experimentally. In the second case we start from an empirical field, domain of experiment and measure, the data processing allowing to establish an empirical model. We can consider that in this case we develop an inductive approach. Of course all these aspects are not requested in a given research, but this process of modeling as a whole is led in a cyclic movement by the scientific community. Note that figure 1 is a model of the modeling activity, which is de facto simplified and limited.

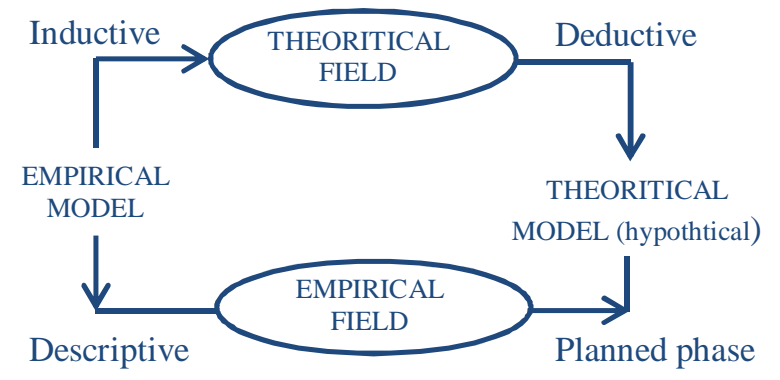

Figure 1. Two opposite starting points (adapted from Walliser, 1977)

Figure 1 describes the scientific process of modeling, but the question of model and modeling is also fundamental for physics teaching. In particular during laboratory sessions, we often follow an inductive approach, for example when we try to develop an empirical model, to establish a law, starting from measurement activities. We discuss in part 2 the question of models in education, relying on two examples corresponding to each of the two modes of modeling exposed above. For each case we discuss the difficulties that can occur for students when they are confronted to such activities.

\subsection{Official instructions}

The terms ñmodels and modelingò are present in the French official instructions already in elementary school. At the end of the period of compulsory education (ninth grade, ages 14ї 15), 
pupils must be able to perform scientific inquiry, in particular ñobserve, question, formulate and validate a hypothesis,é ò and ñmodel in a elementary way [é ]ò[4]. Later, for the ñycéeò (lycée corresponds to students from 15 to 18 years old), the instructions point out the important place given to models and modeling ñ[é ] The teaching of physics and chemistry gives a more important place to laws and models which allow to describe and to plan the nature $\hat{Q}$ behavior (2nde, grade 10)ò [5], and teachers have to introduce pupils to the scientific approach that is to ñallow them to acquire skills about the three essential stages that are observation, modeling and action [é ] (terminale S, grade 12)ò [6]. These extracts correspond to secondary school instructions, but the question of models and modeling is also crucial for higher education teachers, as attested by the results of a research project conducted in a French university with $\mathrm{M}$. Méheut et G. Rebmann [7].

The aim of this project was to assess the effects of a modification of the curricula implemented to fight against the disaffection for scientific studies. For this we followed several cohorts of students, during the first two years of university. The first step of this project was to identify the goals assigned by the teachers to physics education. The two main goals are ñacquisition of scientific behavior and approachesò and ñdevelopment of critical mindò. When teachers explain what they mean we can see that for them the question of model and modeling is essential: acquiring scientific behavior corresponds to learn to observe and model, and developing critical mind corresponds to develop critical attitude towards theories, to learn to discuss about the limits of models and the adequacy of a model for the resolution of a problem.

\section{Studentsôdifficulties}

In this section we present two examples of difficulties encountered by students when they have to model a real problem in the first part, then concerning the understanding of the nature of models, of their modes of elaboration, and of the role of measurement in this process in the second part.

\subsection{Model a real problem}

In the research quoted previously [7], to assess some skills related to modeling activity we proposed successively the same exercise in two different forms (open-ended problem and classical form problem) to $1^{\text {st }}$ and $2^{\text {nd }}$ year university students. The first part is a ñnon-modeledò problem, formulated in common language: ñln the Middle Ages, during a battle, we wish to reach with a catapult a target situated behind ramparts. ò Students have to propose a physical formulation of this problem, for example they can realize a diagram, identify the relevant quantitiesé They have to precise which of these quantities are considered as data and which one as unknown. Then they must solve the problem. This problem corresponds to the end of secondary school level. In the second part we proposed the «same» exercise, that is to say exercise requiring the same physical knowledge, presented as a classical exercise (see Figure 2). In this form the relevant quantities are identified, a diagram is given; the text precises what can be neglected and all the relevant approximations.

We observe for the two exercises very different performances. Among the pupils who solve the modelled exercise (classical problem - they are 19 out of $130-15 \%$ ), 18 out of 19 do 
not manage to express the problem nor to identify and to calculate the relevant quantities in the non-modeled exercise. Most of the students who succeed in solving the second problem had not reformulated or had given an incomplete reformulation in the first part. These students are able to solve the problem if we guide them, but not able to elaborate themselves the stages of resolution.

We consider a moving body $\mathrm{M}$, which can be considered as a material point of mass $\mathrm{m}$. This moving body is placed at a point $\mathrm{O}$ at a distance $\mathrm{d}$ unknown of a wall of height $\mathrm{H}$. It is thrown at the altitude zero with a speed $v_{0}$ making an angle Ǔwith the horizontal in the vertical plane (i, k). We want that it to reach a target C situated at a distance D on the other side of the wall. We shall neglect the frictions of the air and we shall consider that the ground is perfectly horizontal.

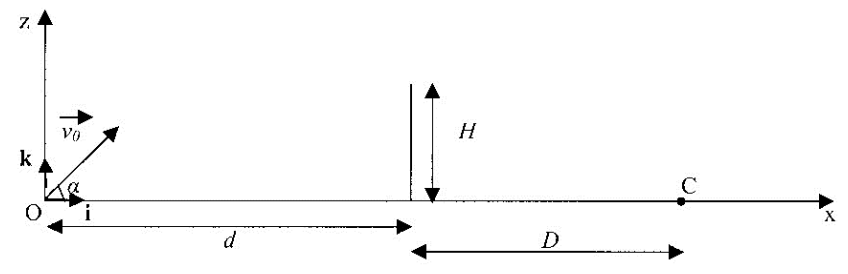

1) Express the acceleration of $M$, then the equations of the movement.

2) Determine the equation of the trajectory of $M$ in $(O, i, k)$.

3) Write the condition that the various quantities have to verify so that $M$ ñfliesò over the wall.

4) Write the condition that the various quantities have to verify so that $\mathrm{M}$ reaches the target $\mathrm{C}$.

Figure 2. Classical exercise

This study shows studentsôvery great difficulties to model a problem. Most of them have not acquired -or are not able to mobilize- many of the skills necessary to model this problem: identification of the relevant quantities, approximationsé

These difficulties of students to mobilize their knowledge to solve problems are well known and have been studied in numerous research about physics education, but these results highlight the "contradiction" between the goals expressed by the teachers (modeling) and the practices, because the second type of exercises (which are the most frequent in the practices) do not allow students to develop and to mobilize the aimed skills. Note that after this study, teachers decided to add more "open problems" (not-modeled exercises) during exercises sessions and to develop open laboratory courses. We can quote for example one teacher: ñ(é ) At the end of each part of laboratory session, we add a session of exercises which was completely connected with the laboratory course and I mean it is good, and it is the way to show them that physics it is modeling and that it works (é )ò.

Of course solving this kind of problem is very long, we cannot limit ourselves to this, but if we do not confront students to such types of problems, they do not succeed in solving them and they do not develop modeling skills. Note that research on physics teaching developed this type of problems and can thus supply tools to university teachers.

\subsection{Understanding the epistemological nature of models: Elaboration of a model from measurement data}

During laboratory activities, students often have to establish models (laws) from measurement data. In this last part we discuss the difficulties that can occur when they are confronted to such activities. 
In physics when we realize manipulations, for example when we measure intensity and tension in a resistive circuit, we obtain points which are not perfectly aligned ${ }^{2}$. The transition from measurement data to models requires the consideration of measurement uncertainties.

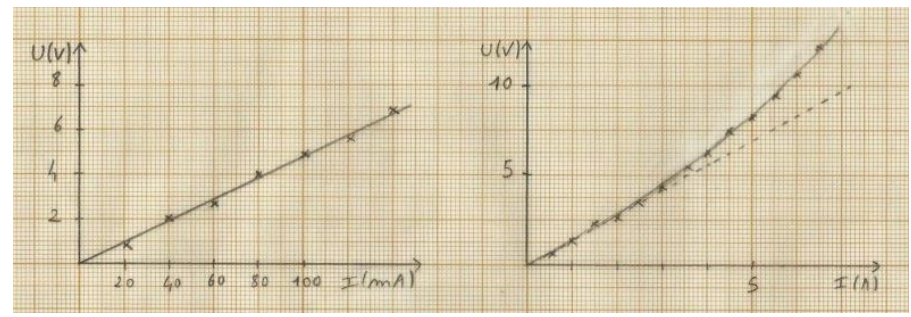

Figure 3.

In the first case we can consider that the law $\mathrm{U}=\mathrm{RI}$ is a "reasonable" model of the relation which connects the quantities intensity and tension in this circuit. In the second case the question is ñFrom which value of the intensity can we consider that this law is not any more a good model of the relation between intensity and tension?ò It means exploring the limits of the model and it cannot be made without estimation of the uncertainties and of the associated confidence interval.

It is classical to encounter during a laboratory session some remarks such as: "It doesnâ work, the points are not aligned", or "It is not normal; we have not the same values as the other groups". Many students are not aware of the natural dispersion of measurement data and have difficulties with measurement process and uncertainties. In several countries, researchers have studied studentsôdifficulties in this area. They categorized the types of reasoning used by pupils and students when they collect data (number of values to collect, etc.), and when they process these data. We present here one of the categorizations which includes three types of student reasoning $[8,9,10]$ :

Point reasoning. For the student, there exists a árue valueô(given in the book or known by the teacher). Any measurement that is different from this correct value is false and is a sign of an error (in the negative meaning of the word). One can access this árue valueôby eliminating errors caused by the measuring system. A single measurement is thus considered sufficient and the result is given in the form of a single value.

Set reasoning. Student begins to see that all measurements are marred by uncertainty and that one needs a large set of data in order to perform a statistical analysis that gives a good approximation of the measurement, as well as a confidence interval. The result of the measurement is expressed in the form of a value accompanied by an interval within which the value is probably located.

Mixed reasoning is an intermediary reasoning.

In a study concerning university students at the freshman level, Lubben and al. showed that more than $30 \%$ of the students mobilize the point reasoning when they collect and process

\footnotetext{
${ }^{2}$ We selected here a very simple example which is relevant of the middle school, but we can find the same type of approach in numerous laboratory courses in higher education (laws of geometrical optics or the friction laws for example).
} 
data [11]. Many other studies have also highlighted pupilsôand studentsôdifficulties in analyzing data and understanding the measuring process. For example the european project đabwork in Science Educationô also demonstrated á lack of explicit understanding of the bases of estimating values from data setsô This research also showed that many high-school and university students (between 30\% and 60\%) áppeared to think that with good enough apparatus and enough care it is possible to make a perfect measurement of a quantityô[12].

We can consider that these difficulties are partially an effect of teaching. Indeed the various quoted researches pointed out that the study of variability of measurement and uncertainties has a reduced place in teachersôpractices. The question of the dispersion is often evacuated or handled mechanically, the causes of the uncertainty are often not analyzed, and the limits of models are rarely explored. This can be explained partially by teachersôdifficulties in addressing the topic of uncertainty in their classrooms. Séré et al. note, for example, that French high-school teachers have á certain reluctance to approach the question of uncertainty with their pupilsô [13], partially because they fear that their students become skeptical about experiment [12].

\section{Discussion}

\subsection{Links between understanding of the role of measurement and the nature of science}

Several researchers $[12,14]$ point out the links between epistemological reflection about the role of measurement and understanding of the nature of sciences. Buffler et al., relying on various studies, describe two profiles for university freshmen, related to their views of the nature of science (NOS) and of the nature of scientific measurement [14]: ñSome students think that nature has its own laws which are discovered though observation, while measurement allows one to obtain óreal valuesô For others, scientific theories are inventions devised by

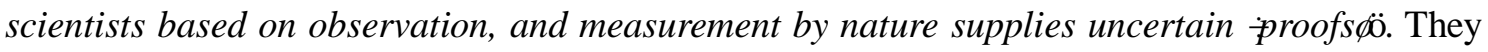
also state that cexplicit exposure to issues about the NOS in laboratory work may help in developing the required understanding of the relationship between scientific claims and experimental datâ̂

We consider that an epistemological reflection about the role of measurement and uncertainties can develop studentsô view of NOS, because it can lead them to a better understanding of the nature of the scientific activity, and particularly of the notion of model. Indeed, we consider that becoming aware of the natural spread of the measures, of the causes of this dispersion, of the gap between model and reality resulting of this dispersion, can contribute to understand what a model is: a tool, build by the scientists, simplified, having a domain of validity, which differs from reality.

That is one of the stakes of physics teaching: develop a view of science more in accordance with contemporary epistemology, in particular help students to understand that one essential activity of scientists is to develop models.

\subsection{Elements of reflection to think a physics teaching taking into account more explicitly the question of models and modeling}


Teachersôquestion should not be only "what models must we teach? ", but "how can we help students to elaborate, to develop and to use models and to understand the nature of these models (constructed, hypothetical, simplified)?ò Some trails are to introduce exercises and laboratory activities in which the modeling is devoted to students, as we discussed in part 2.1. Another one is to articulate several models, compare them, analyze the questions which each of these models allows to deal with and those for whom it is not relevant. These points have been discussed in part 2, but we consider that it is also essential to help students to perceive the gap between model and reality, to help them to identify that a model has a field of application and limits of validity and to develop an explicit work on measurement and uncertainties in connection with the role and the modes of elaboration of models. In a general way we consider that it is essential to introduce elements of epistemology in the curricula, and to develop a reflection on the notion of model in connection with the question of measure and uncertainties.

\section{References}

[1] K. Popper (1982). L'Univers irrésolu. Paris, Hermann.

[2] M.A. Bunge (1975). Philosophie de la physique. Paris, Éd. du Seuil.

[3] B. Walliser (1977). Systèmes et modèles. Paris, Éd. du Seuil.

[4] Ministère de l'Education Nationale, de lâenseignement supérieur et de la recherche (France). (2006). Socle commun de connaissances et de compétences et modifiant le code de lấducation. 11 juillet.

[5] Ministère de lốducation nationale (France). Bulletin officiel spécial n 4 du 29 avril 2010.

[6] Ministère de lấducation nationale (France). Bulletin officiel spécial nº 8 du 13 octobre 2011.

[7] V. Munier, M. Méheut et G. Rebmann (2006). Evaluation de lâmpact dôın changement de programme en physique en 1ère année de DEUG à LôUniversité Paris 7, actes du 23ème colloque international de l'AIPU, Monastir, 15-18 mai 2006.

[8] F. Lubben \& R. Millar (1996). Children's ideas about the reliability of experimental data. International Journal of Science Education, 18(8), 955-968. A sa Place ???

[9] T.S. Volkwyn, S. Allie, A. Buffler, A. Lubben \& B. Campbell (2004). First year physics studentsô understanding of the measurement in the context of laboratory practicals. In A. Buffler \& R.C. Laugksch (Ed). Proceedings of the 12th Annual Conference of the South African Association for Research in Mathematics, Science and Technology Education, p. 1011-1017.

[10] C. Maisch, M. Ney \& N. Balacheff (2008). Quelle est lônfluence du contexte sur les raisonnements dấtudiants sur la mesure en physique? Aster, 47, 43-70.

[11] F. Lubben, B. Campbell, A. Buffler \& S. Allie (2001). Point and Set Reasoning in Practical Science Measurement by Entering University Freshmen. Science Education, 85(4), 311-327.

[12] M.G.Séré, J. Winther, J.F. Le Maréchal \& A. Tiberghien (2001). Le projet européen "Labwork in Science Education" [Les Travaux pratiques dans l'enseignement des sciences en Europe] Bilan et perspectives. Bulletin de l'Union des Physiciens. 839, 1727-1740.

[13] M.G. Séré, R. Journeaux. \& J. Winther (1998). Enquête sur la pratique des enseignants de lycée dans le domaine des incertitudes. Bulletin de l'Union des Physiciens, 801, 247-254.

[14] A. Buffler, F. Lubben \& B. Ibrahim (2009). The relationship between student $\hat{Q}$ views of the nature of science and their views of the nature of scientific measurement. International Journal of Science Education. 31(9), 1137-1156. 